\title{
Article \\ Methicillin-Resistant Staphylococcus aureus from Peninsular Malaysian Animal Handlers: Molecular Profile, Antimicrobial Resistance, Immune Evasion Cluster and Genotypic Categorization
}

\author{
Minhian Chai ${ }^{1}$ (D), Muhammad Zikree Sukiman ${ }^{1}$, Amirah Huda Kamarun Baharin ${ }^{1}$, Insyirah Ramlan ${ }^{1}$, \\ Lennard Zhunhoong Lai ${ }^{1}$, Yeewen Liew ${ }^{1}$, Pavitra Malayandy ${ }^{1}$, Noor Muzamil Mohamad ${ }^{2}$, \\ Siewshean Choong ${ }^{3}$ (D), Siti Mariam Zainal Ariffin ${ }^{4}$ and Mohd Faizal Ghazali ${ }^{1, *(D)}$
}

1 School of Animal, Aquatic and Environmental Sciences, Faculty of Bioresources and Food Industry, Universiti Sultan Zainal Abidin, Besut 22200, Terengganu, Malaysia; amthonychai@gmail.com (M.C.); muhammadzikree@yahoo.com (M.Z.S.); amirahhuda849@gmail.com (A.H.K.B.); insyirahramlan48@gmail.com (I.R.); lennard9714@gmail.com (L.Z.L.); yeewenliew@gmail.com (Y.L.); pavitramalayandy@gmail.com (P.M.)

2 Centralised Laboratory Management Centre, Universiti Sultan Zainal Abidin, Besut 22200, Terengganu, Malaysia; nmuzamil@unisza.edu.my

3 Department of Clinical Studies, Faculty of Veterinary Medicine, Universiti Malaysia Kelantan, Pengkalan Chepa 16100, Kelantan, Malaysia; shean.cs@umk.edu.my

check for updates

Citation: Chai, M.; Sukiman, M.Z.; Kamarun Baharin, A.H.; Ramlan, I.; Lai, L.Z.; Liew, Y.; Malayandy, P.; Mohamad, N.M.; Choong, S.; Ariffin, S.M.Z.; et al. Methicillin-Resistant Staphylococcus aureus from Peninsular Malaysian Animal Handlers: Molecular Profile, Antimicrobial Resistance, Immune Evasion Cluster and Genotypic Categorization. Antibiotics 2022, 11, 103. https:// doi.org/10.3390/antibiotics11010103

Academic Editor: Kunyan Zhang

Received: 1 December 2021

Accepted: 6 January 2022

Published: 14 January 2022

Publisher's Note: MDPI stays neutral with regard to jurisdictional claims in published maps and institutional affiliations.

Copyright: (C) 2022 by the authors. Licensee MDPI, Basel, Switzerland. This article is an open access article distributed under the terms and conditions of the Creative Commons Attribution (CC BY) license (https:// creativecommons.org/licenses/by/ $4.0 /)$.
4 Department of Veterinary Preclinical Sciences, Faculty of Veterinary Medicine, Universiti Putra Malaysia, Serdang 43400, Selangor, Malaysia; sitimariam_za@upm.edu.my

* Correspondence: faizalghazali@unisza.edu.my

\begin{abstract}
Staphylococcus aureus (S. aureus) infections, particularly methicillin-resistant Staphylococcus aureus (MRSA) in humans and animals, have become a significant concern globally. The present study aimed to determine the prevalence and antibiogram of $S$. aureus isolated from animal handlers in Peninsular Malaysia. Furthermore, the genotypic characteristics of $S$. aureus isolates were also investigated. Nasal and oral swab samples were collected from 423 animal handlers in Peninsular Malaysia. The antibiogram profiles of S. aureus against 18 antibiotics were established using a KirbyBauer test. The genotypic profile of $S$. aureus, including the presence of antimicrobial resistance (AMR), virulence genes and spa genotypes, was investigated using molecular techniques. The overall carriage rate of $S$. aureus, MRSA and MDRSA was 30.5\%, $1.2 \%$ and $19.4 \%$, respectively. S. aureus was highly resistant against penicillin (72.3\%) and amoxicillin (52.3\%). Meanwhile, gentamicin and linezolid were fully effective against all the isolated $S$. aureus from animal handlers. It was observed that animal handlers with close exposure to poultry were more likely to carry $S$. aureus that is resistant to tetracycline and erythromycin. S. aureus isolates harboured tetracycline resistance $(t e t \mathrm{~K}$, tet $\mathrm{L}$ and tet $\mathrm{M}$ ), erythromycin resistance (ermA, ermB, erm C and $m s r A$ ) and immune evasion cluster (IEC) genes (scn, chp, sak, sea and sep). Seventeen different spa types were detected among the 30 isolates of MDRSA, with $\mathrm{t} 189$ (16.7\%) and $\mathrm{t} 4171$ (16.7\%) being the predominant spa type, suggesting wide genetic diversity of the MDRSA isolates. The present study demonstrated the prevalence of $S$. aureus strains, including MRSA and MDRSA with various antimicrobial resistance and genetic profiles from animal handlers in Peninsular Malaysia.
\end{abstract}

Keywords: antimicrobial resistance; antibiotic resistance genes; virulence genes; spa typing

\section{Introduction}

Staphylococcus aureus (S. aureus) is an opportunistic, zoonotic pathogen that is capable of causing a wide array of infections, ranging from mild skin infections to life-threatening bacteremia in both humans and animals [1,2]. Recently, the emergence of antimicrobial 
resistance (AMR) in common pathogenic bacteria such as MRSA is considered to be a significant health threat, leading to an increase in healthcare costs, treatment failure and deaths [3]. The issue of AMR is more pressing in low and middle-income countries where the data regarding the burden and epidemiology of AMR bacteria in the community and animals are relatively scarce. S. aureus, especially MRSA infections, has always been a significant problem in both medical settings and the community, due to its ability to show multiple resistance to various antibiotics, especially towards beta-lactam antibiotics [4]. However, with the recent emergence of multidrug-resistant $S$. aureus strains, such as livestock-associated MRSA (LA-MRSA) in animals, animal handlers such as veterinarians and farmers are equally at risk of being colonized and infected by AMR strains originating from animals [5-7]. Previous studies have shown that the prevalence of S. aureus among pig farmers ranged from $26.1 \%$ to $57.0 \%$ [8,9]. Meanwhile, the carriage of MRSA among pig farmers ranged from $2.5 \%$ to $6.7 \%$ [8,9]. Nonetheless, Oppliger and co-authors reported a higher carriage rate of $S$. aureus and MRSA among farmers and veterinarians as compared to individuals without contact with pigs, indicating that constant exposure to animals may be a risk for $S$. aureus colonization [8]. In addition, Wardy et al. (2015) reported that people with current swine exposure were significantly more likely to carry S. aureus, tetracycline-resistant $S$. aureus (TRSA), multidrug-resistant S. aureus (MDRSA) and livestockassociated S. aureus (LA-SA) than individuals that lacked exposure [9]. It was found that the transmission of MRSA from animals to humans could occur via three routes: direct contact with livestock and pet animals and environmental contamination [4]. Moreover, multiple studies have shown that the handling or consumption of animal products such as raw milk, meat and cheese products can cause the transmission of $S$. aureus and MRSA from animal origin to the human community $[2,10,11]$.

In the last d-ecade, there have been reports of the increasing epidemiological risk of $S$. aureus, particularly from strains that have acquired antimicrobial resistance (AMR) genes $[4,12,13]$. Previous studies reported that $S$. aureus had acquired resistance to multiple antibiotics (multidrug resistance) through the acquisition of AMR genes that respond to different groups of antibiotics [14]. This is true, especially in the case of methicillin-resistant $S$. aureus when the mecA gene was found to be responsible for the resistant trait against beta-lactam antibiotics, including methicillin, penicillin, oxacillin and cefoxitin $[15,16]$. In addition, methicillin-susceptible $S$. aureus (MSSA) was frequently reported to be harboring AMR genes from other groups of antibiotics simultaneously, including tetracyclines and macrolides $[15,17,18]$. In addition, $S$. aureus is also capable of producing multiple virulence factors that increase the pathogenicity of the bacteria [4]. These virulence factors include proteins that evade the human host immune responses and promote the colonization of the bacteria to the host cells, enzymes that induce cytolytic effects, as well toxins that induce inflammatory effects and toxic shock syndrome $[12,15,19]$. Five of these factors include staphylococcal complement inhibitory protein (SCIN), staphylokinase (SAK), chemotaxis inhibitory protein (CHIPS), staphylococcal enterotoxin type A (SEA) and staphylococcal enterotoxin type $\mathrm{P}$ (SEP). These five immune evasion modulators are encoded by a group of genes called immune evasion cluster (IEC), consisting of scn, chp, sak, sea and sep. Past studies reported that IEC genes were frequently found in S. aureus lineages well adapted to humans, but not in livestock-associated S. aureus and LA-MRSA strains [19-21]. Another important virulence factor produced by $S$. aureus is Panton-Valentine leukocidin (PVL) encoded by $l u k F / l u k S-P V$ gene, a bi-component pore-forming toxin capable of causing the destruction and lysis of leukocytes [12]. In addition, toxic shock syndrome toxin-1 (TSST-1), which is encoded by the tst gene, is one of the most important pyrogenic toxin superantigens (PTSAgs) produced by S. aureus that may lead to high fever, diffuse erythematous rash, desquamation of the skin after onset and hypotension [22]. Meanwhile, Staphylococcal exfoliative toxins (ETs) encoded by eta and etb genes are responsible for skin and soft tissue infections such as Staphylococcal scalded skin syndrome (SSSS) [23]. In Malaysia, most of the $S$. aureus AMR surveillance studies were mainly conducted in patients, medical staff or students with constant exposure to the medical settings [18,24]. Furthermore, 
the majority of AMR surveillance and genotypic studies tend to focus more on MRSA isolates rather than methicillin-susceptible S. aureus (MSSA) isolates [24]. As a result, the previous findings may not necessarily reflect the actual overall AMR status of the S. aureus in relatively healthy human populations, particularly in Malaysian animal handlers. Until 2018, the prevalence rate of MRSA among S. aureus isolated from human patients and university students ranged from $15.0 \%$ to $28.1 \%$ [10,14]. In addition, it was also revealed that the clinical MRSA isolates from several hospitals in Malaysia were highly resistant against penicillin $(100 \%)$, macrolides $(>70 \%)$ and fluoroquinolone (>59\%) antibiotics [14]. Furthermore, data regarding the latest antibiogram and antimicrobial resistance genes profile of S. aureus from animal handlers in Malaysia remain scarce. This creates knowledge gaps on the data concerning antimicrobial resistance and the genotypic profile of Malaysian MSSA isolates. Realizing this knowledge gap, the present study was carried out with the aim to determine the carriage rate, phenotypic antimicrobial resistance profile and genotypic characteristics of $S$. aureus isolated from animal handlers in Peninsular Malaysia.

\section{Results}

\subsection{Carriage Rate of S. aureus and MRSA from Animal Handlers}

Among the 846 swab samples, 155, or $18.3 \%$ (155/846; 95\% CI: 15.8-20.8\%), swabs were found harbouring $S$. aureus via polymerase chain reaction (PCR) screening of the nuc gene and considered to be $S$. aureus positive. These 155 isolates originated from 129 individuals; thus, the overall prevalence rate of S. aureus is 30.5\% (129/423; 95\% CI: 26.2-34.8\%). Eightythree $S$. aureus isolates originated from nasal (19.6\%, 83/423; 95\% CI: 11-28.2\%) while 72 isolates originated from oral swab samples (17\%, 72/423; 95\% CI: 13.5-20.5\%). Twenty (4.7\%, 20/423; 95\% CI: 2.7-6.7\%) individuals were carrying S. aureus in both the nasal and oral parts. Further PCR assay revealed that six (3.8\%, 6/155; 95\% CI: 0.9-6.7\%) S. aureus isolates were mecA gene positive, indicating the presence of MRSA among five animal handlers $(1.2 \% ; 5 / 423)$. Five of the MRSA isolates were from nasal $(1.2 \%, 5 / 423 ; 95 \%$ CI: $0.2-2.2 \%)$ while only one was from oral swab $(0.2 \%, 1 / 423 ; 95 \%$ CI: $0-0.6 \%)$ samples. The $S$. aureus and MRSA carriage rates of veterinarians, pet owners and animal farmers are shown in Table 1. Statistical analysis revealed that there is no significant difference between the carriage rates of $S$. aureus and MRSA in categorical variables $(p>0.05)$.

Table 1. The carriage rates of S. aureus, MRSA and MDRSA among animal handlers $(n=423)$ according to sample groups (veterinarians, pet owners and animal farmers).

\begin{tabular}{ccccc}
\hline No. & Sample Groups & $\begin{array}{c}\text { S. aureus Positive } \\
\mathbf{( \% ;} \mathbf{9 5} \mathbf{C I})\end{array}$ & $\begin{array}{c}\text { MRSA Positive } \\
\mathbf{( \% ;} \mathbf{9 5 \%} \text { CI) }\end{array}$ & $\begin{array}{c}\text { MDRSA Positive } \\
(\mathbf{\%} ; \mathbf{9 5} \% \mathbf{C I})\end{array}$ \\
\hline 1. & Veterinarians $(n=10)$ & $3(30.0 ; 1.0-58.4 \%)$ & $0(0 ; 0 \%)$ & $2(20.0 ; 0-44.8 \%)$ \\
2. & Pet owners $(n=70)$ & $20(28.6 ; 18.0-39.2 \%)$ & $1(1.4 ; 0-4.2 \%)$ & $7(10.0 ; 3.0-17.0 \%)$ \\
3. & Animal farmers $(n=343)$ & $105(30.6 ; 25.7-35.5 \%)$ & $4(1.2 ; 0-2.4 \%)$ & $21(6.1 ; 3.6-8.6 \%)$ \\
& Total $(n=423)$ & $129(30.5 ; 26.2-34.8 \%)$ & $5(1.2 ; 0.2-2.2 \%)$ & $30(7.1 ; 4.7-9.5 \%)$ \\
\hline
\end{tabular}

\subsection{Antibiotic Susceptibility Profile of S. aureus and MRSA from Animal Handlers}

The antibiotic susceptibility testing result of $S$. aureus was summarized in Table 2 . In the current study, $80.0 \%(124 / 155)$ of $S$. aureus isolates showed resistance against one or more antibiotics. The findings also revealed that $S$. aureus showed the highest resistance rate towards penicillin $(72.3 \%, 112 / 155 ; 95 \%$ CI: $65.2-79.4 \%)$ and amoxicillin $(53.5 \%, 83 / 155$; 95\% CI: 45.7-61.3\%). Meanwhile, MRSA isolates showed the highest resistance rate against penicillin $(100 \% ; 6 / 6)$, cefoxitin $(100 \% ; 6 / 6)$, amoxicillin $(83.3 \%, 5 / 6 ; 95 \%$ CI: $53.5-100 \%)$ and chloramphenicol (50.0\%, 3/6; 95\% CI: 10.0-90.0\%). Gentamicin and linezolid were fully effective (100\% susceptible) against all the isolated $S$. aureus from animal handlers. In addition, no significant differences were observed when comparing the antibiotic resistance profile of the $S$. aureus according to categories of animal handlers (veterinarian, pet owner and animal farmer). However, individuals with constant contact with poultry $(7 / 22 ; 31.8 \%)$ 
were more likely to carry $S$. aureus that showed resistance against tetracycline as compared to ruminants $(8 / 77 ; 10.4 \%)$ and pet animals $(3 / 20 ; 15.0 \%)$. Similarly, S. aureus from animal handlers with constant contact with poultry $(11 / 22 ; 50 \%)$ showed a higher resistance rate against erythromycin as compared to ruminants $(4 / 77 ; 5.2 \%)$ and pet animals $(6 / 17 ; 35.3 \%)$ handlers. Meanwhile, individuals with constant exposure to ruminant animals (34/77; $44.2 \%$ ) were less likely to carry $S$. aureus resistant to penicillin compared to poultry handlers $(19 / 22 ; 86.4 \%)$, pet owners $(18 / 20 ; 90.0 \%)$ and aquatic animal handlers $(6 / 9 ; 66.7 \%)$. In the present study, $19.4 \%$ (30/155; 95\% CI: 13.2-25.6\%) of S. aureus isolates were categorised as multidrug resistant as they showed resistance to antibiotics from three different groups of antibiotics. The MDRSA prevalence rates of veterinarians, pet owners and animal farmers were summarized in Table 1. No significant difference was observed when comparing the carriage rate of MDRSA according to sample groups (veterinarian, pet owner and animal farmer). Multiple antimicrobial resistance index (MARI) assessment (Table 3) revealed that 26 (16.8\%; CI: 10.9-22.7\%) out of 155 S. aureus isolates have an MARI value of 0.2 and above. The relatedness of the $S$. aureus isolates based on their phenotypic antibiotic resistance pattern were displayed in the dendrogram (Figure 1) generated using the unweighted pair group method with arithmetic mean (UPGMA), showing that two major clusters can be formed among the isolates.

Table 2. Antibiogram of $S$. aureus $(n=155)$ isolated from animal handlers in Peninsular Malaysia.

\begin{tabular}{lccc}
\hline \multicolumn{1}{c}{ Antimicrobials } & \multicolumn{3}{c}{ Number of Isolates (\%) } \\
\cline { 2 - 4 } & Resistant & Intermediate & Susceptible \\
\hline Penicillin & $112(72.3)$ & $0(0)$ & $43(27.7)$ \\
Amoxicillin & $83(53.5)$ & $0(0)$ & $72(46.5)$ \\
Erythromycin & $22(14.2)$ & $8(5.2)$ & $125(80.6)$ \\
Clindamycin & $19(12.3)$ & $14(9.0)$ & $122(78.7)$ \\
Cefoxitin & $18(11.6)$ & $0(0)$ & $137(88.4)$ \\
Tetracycline & $18(11.6)$ & $4(2.6)$ & $133(85.8)$ \\
Quinupristin/Dalfopristin & $12(7.7)$ & $1(0.6)$ & $142(91.6)$ \\
Chloramphenicol & $10(6.5)$ & $4(2.6)$ & $141(90.9)$ \\
Cephalothin & $8(5.2)$ & $0(0)$ & $147(94.8)$ \\
Cefotaxime & $7(4.5)$ & $16(10.3)$ & $132(85.2)$ \\
Norfloxacin & $6(3.9)$ & $2(1.3)$ & $147(94.8)$ \\
Doxycycline & $5(3.2)$ & $4(2.6)$ & $146(94.2)$ \\
Ciprofloxacin & $5(3.2)$ & $0(0)$ & $150(96.8)$ \\
Trimethoprim/sulfamethoxazole & $4(2.6)$ & $2(1.3)$ & $149(96.1)$ \\
Amikacin & $2(1.3)$ & $0(0)$ & $153(98.7)$ \\
Gentamicin & $0(0)$ & $0(0)$ & $155(100)$ \\
Linezolid & $0(0)$ & $0(0)$ & $155(100)$ \\
\hline
\end{tabular}

Resistant $=\mathrm{R}$; Intermediate $=\mathrm{I}$; Susceptible $=\mathrm{S}$; Penicillin: $\mathrm{R} \leq 28 \mathrm{~mm}, \mathrm{~S} \geq 29 \mathrm{~mm}$; Amoxicillin: $\mathrm{R} \leq 19 \mathrm{~mm}$ $\mathrm{S} \geq 20 \mathrm{~mm}$; Erythromycin: $\mathrm{R} \leq 13 \mathrm{~mm}, \mathrm{I}=14-22 \mathrm{~mm}, \mathrm{~S} \geq 23 \mathrm{~mm}$; Clindamycin: $\mathrm{R} \leq 14 \mathrm{~mm}, \mathrm{I}=15-20 \mathrm{~mm}$, $\mathrm{S} \geq 21 \mathrm{~mm}$; Cefoxitin: $\mathrm{R} \leq 21 \mathrm{~mm}, \mathrm{~S} \geq 22 \mathrm{~mm}$; Tetracycline: $\mathrm{R} \leq 14 \mathrm{~mm}, \mathrm{I}=15-18 \mathrm{~mm}, \mathrm{~S} \geq 19 \mathrm{~mm}$; Quinupristin/Dalfopristin: $\mathrm{R} \leq 15 \mathrm{~mm}, \mathrm{I}=16-18 \mathrm{~mm}, \mathrm{~S} \geq 19 \mathrm{~mm}$; Chloramphenicol: $\mathrm{R} \leq 12 \mathrm{~mm}, \mathrm{I}=13-17 \mathrm{~mm}$, $\mathrm{S} \geq 18 \mathrm{~mm}$; Cephalothin: $\mathrm{R} \leq 14 \mathrm{~mm}, \mathrm{I}=15-17 \mathrm{~mm}, \mathrm{~S} \geq 18 \mathrm{~mm}$; Cefotaxime: $\mathrm{R} \leq 14 \mathrm{~mm}, \mathrm{I}=15-22 \mathrm{~mm}$, $\mathrm{S} \geq 23 \mathrm{~mm}$; Norfloxacin: $\mathrm{R} \leq 12 \mathrm{~mm}, \mathrm{I}=13-16 \mathrm{~mm}, \mathrm{~S} \geq 17 \mathrm{~mm}$; Doxycycline: $\mathrm{R} \leq 12 \mathrm{~mm}, \mathrm{I}=13-15 \mathrm{~mm}$, $\mathrm{S} \geq 16 \mathrm{~mm}$; Ciprofloxacin: $\mathrm{R} \leq 15 \mathrm{~mm}, \mathrm{I}=16-20 \mathrm{~mm}, \mathrm{~S} \geq 21 \mathrm{~mm}$; Trimethoprim/Sulfamethoxazole: $\mathrm{R} \leq 10 \mathrm{~mm}$, $\mathrm{I}=11-15 \mathrm{~mm}, \mathrm{~S} \geq 16 \mathrm{~mm}$; Amikacin: $\mathrm{R} \leq 14 \mathrm{~mm}, \mathrm{I}=15-16 \mathrm{~mm}, \mathrm{~S} \geq 17 \mathrm{~mm}$; Gentamicin: $\mathrm{R} \leq 12 \mathrm{~mm}$, $\mathrm{I}=13-14 \mathrm{~mm}, \mathrm{~S} \geq 15 \mathrm{~mm}$; Linezolid: $\mathrm{R} \leq 20 \mathrm{~mm}, \mathrm{~S} \geq 21 \mathrm{~mm}$. 
Table 3. MARI assessment of $S$. aureus $(n=155)$ isolated from animal handlers.

\begin{tabular}{cccc}
\hline Number of Antibiotic & MARI Value & Number of Isolates & Total (\%) \\
\hline 0 & 0 & 31 & 20.0 \\
1 & 0.06 & 33 & 21.3 \\
2 & 0.11 & 51 & 32.9 \\
3 & 0.16 & 14 & 9.0 \\
4 & 0.22 & 9 & 5.8 \\
5 & 0.27 & 6 & 3.8 \\
6 and above & 0.33 & 11 & 7.1 \\
\hline
\end{tabular}

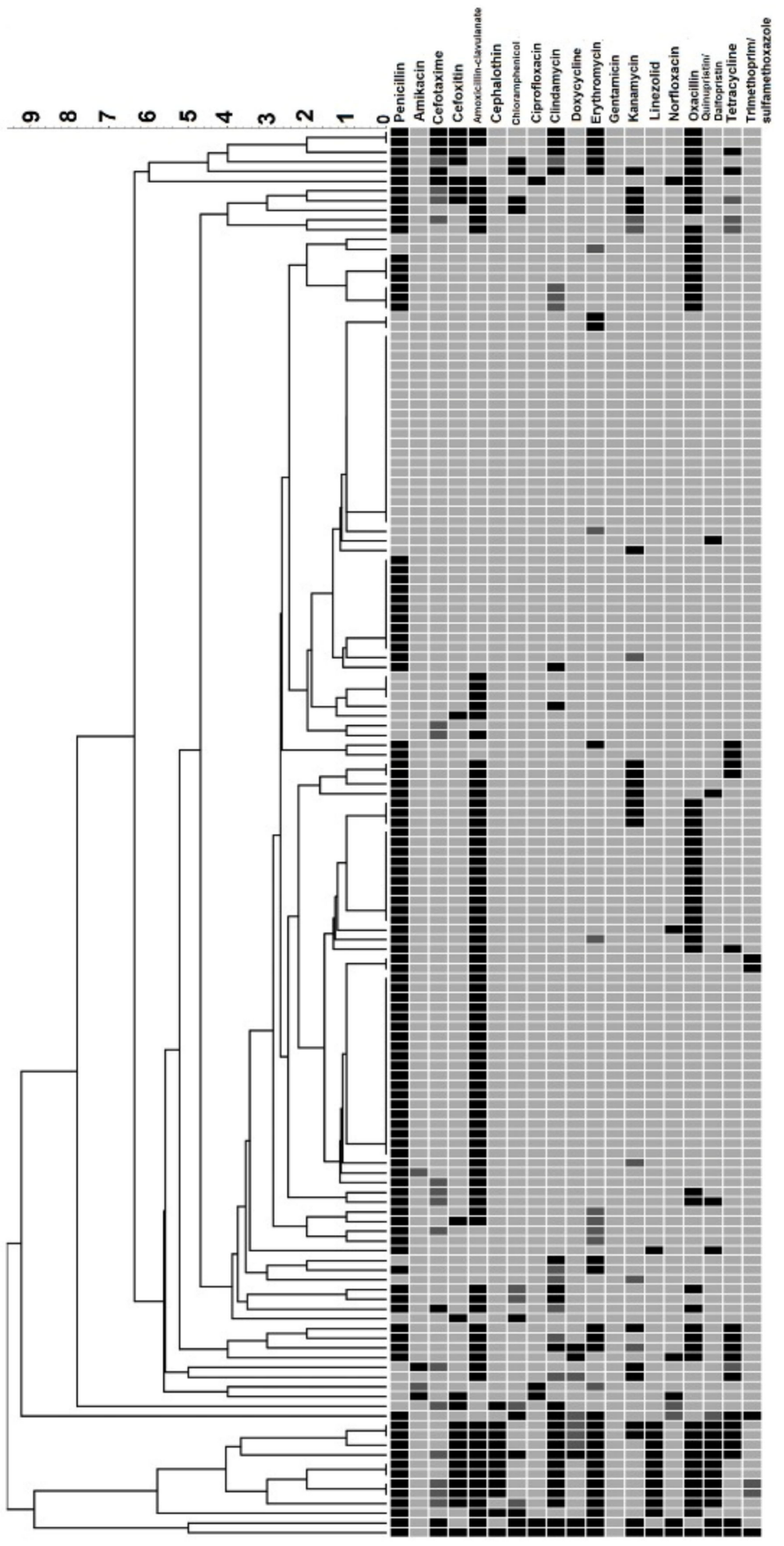

Figure 1. Dendrogram illustrating the relatedness of $S$. aureus based on phenotypic antibiotic resistance pattern. Black = resistant; dark grey $=$ intermediate and light grey $=$ susceptible . 


\subsection{Genotypic Characterization of $S$. aureus}

In the current study, $12(7.7 \% ; 12 / 155)$ of the $S$. aureus isolates were found harbouring tet genes, where $3.2 \%(5 / 155)$ of the isolates carried the tetK genes, four $(2.6 \% ; 4 / 155)$ carried the tetL genes while only one $(0.6 \% ; 1 / 155)$ isolate was harbouring tetM gene. In addition, the prevalence rate of ermA, ermB, ermC and msrA genes were $1.3 \%(2 / 155)$, $1.3 \%(2 / 155), 4.5 \%(7 / 155)$ and 3.2\% (5/155), respectively. Both vanA and mecC genes were not detected among the isolated $S$. aureus.

In regard to virulence genes, $44.5 \%(69 / 155)$ of $S$. aureus collected from animal handlers contained at least one of the five IEC genes (scn, chp, sak, sea or sep). Furthermore, three out of six MRSA isolates were found harbouring IEC genes. The scn genes were detected in 53 isolates $(36.8 \% ; 53 / 155)$, while the occurrence rates of sak and chp genes were $30.3 \%$ $(47 / 155)$ and $8.4 \%(13 / 155)$, respectively. A low number of sea $(0.6 \% ; 1 / 155)$ and sep $(0.6 \%$; $1 / 155)$ genes were detected from two different $S$. aureus isolates. No IEC genes were found among the 71 (68 MSSA and 3 MRSA) isolates. Fifty $S$. aureus isolates with the presence of scn were later categorised into IEC types. The predominant IEC type in this study was type $H$ (21 isolates), as shown in Table 4 . Meanwhile, the predominant IEC type among MDRSA isolates was type E (5/30) as shown in Table S1. The luk-PV, tst, eta and etb genes were not detected from the $155 \mathrm{~S}$. aureus isolates.

Table 4. Summary of IEC types of $S$. aureus isolates $(n=155)$.

\begin{tabular}{ccccc}
\hline \multirow{2}{*}{ IEC Type } & \multirow{2}{*}{$\begin{array}{c}\text { IEC Genes } \\
\text { Composition }\end{array}$} & \multicolumn{2}{c}{ Number of Isolates (\%) } & \multirow{2}{*}{$\begin{array}{c}\text { Total Number } \\
\text { of Isolates (\%) }\end{array}$} \\
\cline { 3 - 4 } & MSSA ( $\mathbf{n = 1 4 9 )}$ & MRSA ( $\mathbf{n = 6 )}$ & $1(0.6)$ \\
A & scn, chp, sak, sea & $1(6.7)$ & $0(0)$ & $10(6.5)$ \\
$\mathrm{B}$ & scn, chp, sak & $10(6.7)$ & $0(0)$ & $0(0)$ \\
$\mathrm{C}$ & scn, chp & $0(0)$ & $0(0)$ & $0(0)$ \\
$\mathrm{D}$ & scn, sak, sea & $0(0)$ & $0(0)$ & $19(12.3)$ \\
$\mathrm{E}$ & scn, sak & $17(11.4)$ & $2(33.3)$ & $0(0)$ \\
$\mathrm{F}$ & scn, chp, sak, sep & $0(0)$ & $0(0)$ & $1(0.6)$ \\
G & scn, sak, sep & $1(6.7)$ & $0(0)$ & $21(13.5)$ \\
H & Scn & $21(14.1)$ & $1((16.7)$ & $71(11.0)$ \\
Non-typable & Absent of scn gene & $17(11.4)$ & $0(0)$ & $71(45.8)$ \\
No Type & Absent of all & $68(45.6)$ & $3(50.0)$ & \\
\hline
\end{tabular}

Thirty of the multidrug-resistant S. aureus (MDRSA) isolates (5 MRSA and 25 MDRMSSA) were characterized using spa typing (Figure 2). Seventeen different spa types were identified, with the most prominent spa types identified being $\mathrm{t} 189(16.6 \% ; 5 / 31)$ and $\mathrm{t} 4171$ $(16.6 \% ; 5 / 31)$. Other spa types included t2174 (12.9\%; 4/31), t3080 (6.5\%; 2/31), t3293 (6.5\%; 2/31), t050 (3.2; 1/31), t550 (6.5\%; 1/31), t084 (3.2; 1/31), t091 (3.2; 1/31), t127 (3.2; 1/31), t315 (3.2; 1/31), t548 (3.2; 1/31), t605 (3.2; 1/31), t714 (3.2; 1/31), t3937 (3.2; 1/31), t4720 $(3.2 ; 1 / 31)$ and $t 9531(3.2 ; 1 / 31)$. Among the MRSA group, four different spa types were identified, including $\mathrm{t} 189(n=2), \mathrm{t} 3293(n=2), \mathrm{t} 4171(n=1)$, and $\mathrm{t} 3080(n=1)$. Based on Figure 2 it was observed that the MDRSA isolates can be divided into three major clusters where $\mathrm{t} 714, \mathrm{t} 4171, \mathrm{t} 4720, \mathrm{t} 3937$ and $\mathrm{t} 3293$ belong to cluster 1 . The spa types $\mathrm{t} 189, \mathrm{t} 2174, \mathrm{t} 315$ and $\mathrm{t} 548$ were grouped into cluster 2 , while $\mathrm{t} 3080, \mathrm{t} 605, \mathrm{t} 084, \mathrm{t} 9531, \mathrm{t} 127, \mathrm{t} 091, \mathrm{t} 050$ and $\mathrm{t} 550$ were categorized into cluster 3. The genotypic profiles of MRSA and MDR-MSSA from animal handlers in Peninsular Malaysia were shown in Table S1. Based on the findings, it was observed that genotypic profiles of the MDRSA were different, with the exception of MRSA 3 and MRSA 4. 


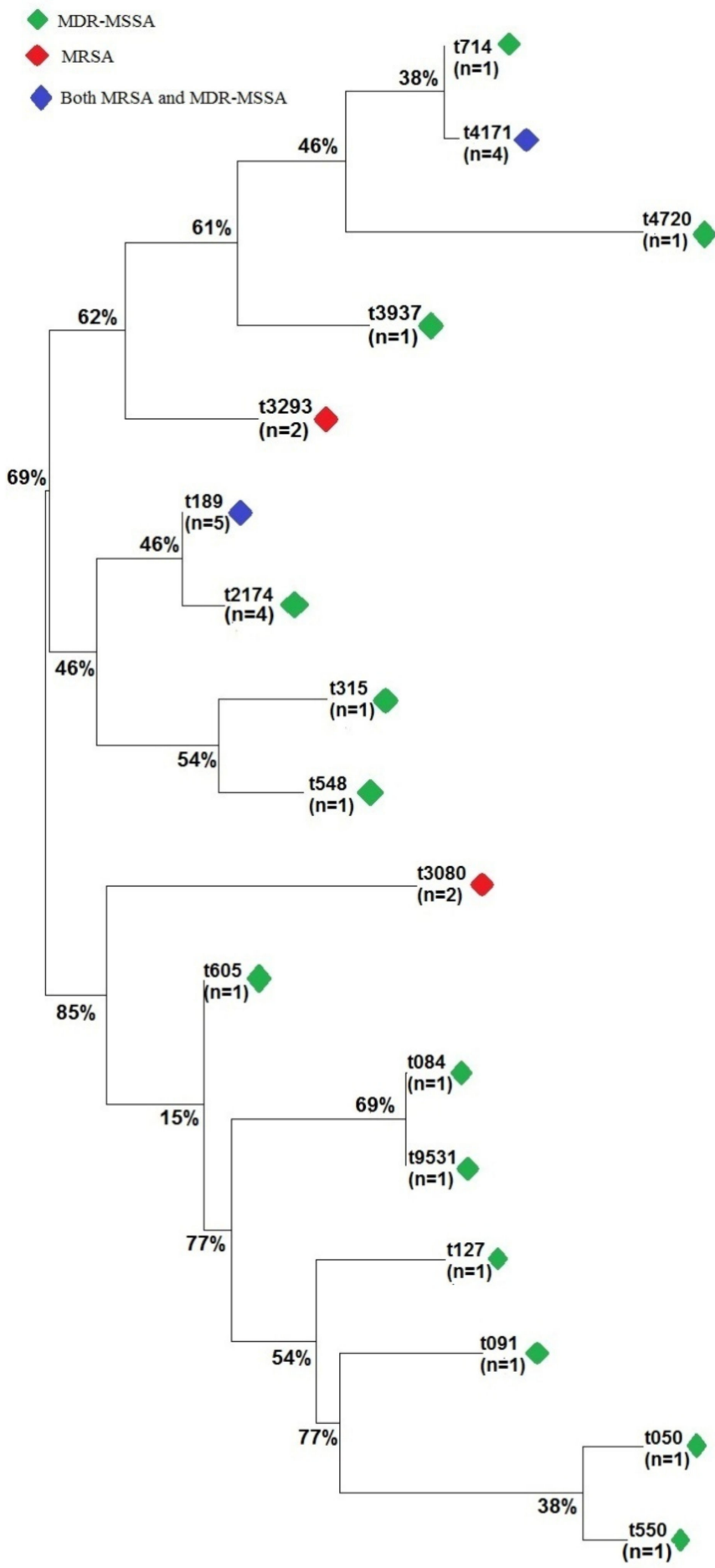

$\begin{array}{lllll}0.080 & 0.060 & 0.040 & 0.020 & 0.000\end{array}$

Figure 2. The phylogenetic tree of the spa types of MDRSA isolates was constructed using MEGA version 10. The evolutionary history was inferred using the neighbor-joining method. The optimal tree with the sum of the branch length $=0.45581958$ is shown. The tree is drawn to scale, with branch lengths in the same units as those of the evolutionary distances used to infer the phylogenetic tree. The evolutionary distances were computed using the maximum composite likelihood method and are in the units of the number of base substitutions per site. 


\section{Discussion}

Since its first discovery, information regarding S. aureus strains, especially MRSA, has rapidly changed around the globe [25]. Thus, continuous surveillance of S. aureus and MRSA in different communities is highly required to obtain the latest data regarding the prevalence, antibiogram profile and genotypic characteristics of these bacteria. Moreover, the antibiogram profiles obtained in this study can be used to better understand the AMR status of $S$. aureus in a relatively healthy community and as a reference to select the best antibiotics for the successful treatment of $S$. aureus and MRSA infection in Malaysian animal handlers.

The prevalence rate of $S$. aureus among animal handlers reported in this study is within the range of the reported $20 \%$ to $30 \%$ nasal carriage rate in the United States and European countries [26]. However, there is also a wide range in the nasal S. aureus carriage rate among European countries, with the Hungarian participants having a significantly lower S. aureus prevalence rate $(12.1 \%)$ as compared to a $29.4 \%$ carriage rate among participants from Sweden [26]. In Malaysia, findings regarding the carriage rate of S. aureus among local individuals with constant exposure to animals such as farmers, pet owners and veterinarians need to be updated. Furthermore, the sample sizes of animal handlers in the previous studies were relatively small (less than 100 participants), with more emphasis on MRSA isolates [27,28]. In 2013, Neela and co-authors reported that only three (3.61\%; $3 / 83$ ) S. aureus samples were isolated from Malaysia poultry farm workers, with none of the isolates being mecA positive [27]. Another study by Akilu and his co-authors (2012) demonstrated a higher MRSA prevalence rate, where $7.1 \%(2 / 28)$ of staff from University Veterinary Hospital of Universiti Putra Malaysia were found to be MRSA positive as compared to the $1.2 \%$ recorded in this study [28]. Nonetheless, a study conducted in the Netherlands reported a lower carriage rate, where $0.6 \%$ of adults living in close proximity to livestock farms were colonized with MRSA [7]. The reasons for the low MRSA carriage rate presented in this study remain unknown. However, it is agreed that factors such as genetic factors, environmental factors, type of samples or sampling sites (only on one site or multiple sites including the anterior nares, pharynx, skin and perineum), cultivation of bacteria (with or without enrichment) and study design (cohort study with repeated sampling or cross-sectional study with one-time sampling) can influence the results of such studies [26].

In the current study, S. aureus from animal handlers showed resistance against 18 different antibiotics, with $19.4 \%(30 / 155)$ of $S$. aureus isolates categorised as multidrug resistant. This finding is similar to the $19.4 \%$ MDRSA prevalence rate among individuals with close contact with livestock [9]. Antibiotic susceptibility tests revealed that $S$. aureus from animal handlers was highly resistant to penicillin (72.3\%). This finding is lower than the $90 \%$ to $100 \%$ penicillin resistance rate among S. aureus from hospital and university students in Malaysia [18,29]. Meanwhile, MRSA isolates showed a high resistance rate against beta-lactam antibiotics, particularly penicillin $(100 \% ; 6 / 6)$, cefoxitin $(100 \% ; 6 / 6)$ and amoxicillin/clavulanate $(83.3 \% ; 5 / 6)$. This is not surprising as MRSA strains are often resistant to nearly all of the beta-lactam antibiotics due to the production of PBP2a [2]. Despite that, all of the S. aureus isolates were fully sensitive towards linezolid and gentamicin, suggesting that these antibiotics can be used to treat persistent $S$. aureus infections among animal handlers. Nonetheless, as clinical tests were not carried out in the study, the effectiveness of these antibiotics against $S$. aureus infections remains inconclusive. Further MAR index assessment revealed that $16.7 \%$ S. aureus had an index value of 0.2 and above. MAR index values of 0.2 and above have been used to differentiate low- and high-risk regions where antibiotics are overused, thus suggesting that $16.7 \%$ of the S. aureus isolates from Malaysian animal handlers were exposed to environments with high antibiotic use and high selective pressure [30]. The main reason for the presence of $S$. aureus strains that exhibit phenotypic resistance traits among local animal handlers remains uncertain. It is well known that repeated therapeutic and indiscriminate usage of antibiotics will cause the development of antimicrobial resistance in microorganisms [31]. In the present study, 
the majority of participants $(81.4 \%$ ) declared that no antibiotics were used by themselves within a three-month period. Furthermore, no significant differences were observed when analysing the carriage rate of MDRSA or S. aureus with AMR traits according to the usage of antibiotics within a three-month period, suggesting short-term antibiotic usage alone was unlikely to cause the emergence of AMR. However, it is possible that these participants were colonized by $S$. aureus with AMR traits through direct contact with infected animals or humans with a prolonged antibiotic usage history, environmental agents and animal food products contaminated with AMR bacteria [10,11,32-34]. In the present study, S. aureus from individuals with exposure to poultry were found to have a higher resistance rate against tetracycline and erythromycin as compared to other animal species, suggesting there might be a relationship between these two variables. Previous research has indicated that individuals that were frequently exposed to live poultry were more likely to carry livestock-associated S. aureus strains, such as LA-MRSA [35]. In Malaysia, antimicrobials such as erythromycin and tetracycline antibiotics were permitted to be used in poultry for both disease treatment and prevention purposes [27]. Hence, there is a possibility that $S$. aureus with erythromycin- and tetracycline-resistant traits may have originated from the poultry. However, as no samples were collected from the animals, it is uncertain that the $S$. aureus from poultry origins may be presented with the similar antibiotic resistance pattern. Thus, it would be beneficial for future studies to collect samples from various sources (human, animals and environments) over a longer period to determine the possible origin of AMR bacteria. In most of the cases, phenotypic antibiotic resistance is encoded by the various antimicrobial resistance genes found within the bacteria. Thus, it is coherent to speculate that $S$. aureus isolates resistant against these antibiotics may harbour antimicrobial resistance genes that encode for defensive mechanisms, including the production of defensive enzymes, reduced permeability, enzymatic inactivation, efflux pumps or ribosomal protection [14]. In the present study, mec $A$, tetK, tet $L$, tet $M, \operatorname{erm} A, \operatorname{erm} B, \operatorname{erm} C$ and $m s r A$ genes were detected. The tet $\mathrm{K}$ and tet $\mathrm{L}$ genes are responsible for the tetracycline efflux pump system, while tet $\mathrm{M}$ is involved in ribosomal protection [14]. Meanwhile, ermA, ermB and erm $C$ genes are responsible for the ribosomal binding site modification to protect the $S$. aureus against erythromycin antibiotics, while the $m s r A$ gene encodes for an ATP-dependent efflux pump [36]. The $S$. aureus isolates in this study displayed a higher prevalence of erm C (4.5\%; 7/155). This finding is in agreement with a study in South Africa where the erm $C$ gene is the most frequently found macrolide-lincosamide resistance gene in pigs [36]. Nonetheless, it is observed that certain isolates did not harbour the antimicrobial resistance genes despite showing phenotypic resistance. It is possible that the phenotypic resistance of these isolates may be mediated by resistance genes or mechanisms that are not included in study $[37,38]$.

Immune evasion virulence factor is one of the many vital factors that enable $S$. aureus to adapt and survive in the human host. IEC has been shown to play an essential role in the disruption or inhibition of the normal function of the human immune system, as well as causing food poisoning [20]. Thus, the presence of IEC genes is believed to facilitate the colonization and invasion of $S$. aureus in human hosts. In addition, the absence of $s c n$ gene in $S$. aureus is considered to be a marker and strong indicator for livestock-derived strains $[9,19]$. The screening of IEC genes in S. aureus isolates showed that $44.5 \%(69 / 155)$ of isolates collected from animal handlers were found to contain at least one of the IEC genes, with the predominant IEC type in this study being Type H. This finding is different compared to other studies that recorded a high prevalence of IEC genes in clinical S. aureus $(>75 \%)$ isolates, with the predominant IEC type being Type B [20,39]. However, several studies have also demonstrated that isolates from humans with occupational exposure to animals may not harbour the IEC genes, possibly due to the transmission and colonization of $S$. aureus from animals $[19,21]$. Further analysis of IEC composition among MDRSA (Table S1) also revealed that more than half $(56.7 \% ; 17 / 30)$ of the isolates were lacking IEC genes, highlighting the possibility of transmission of MDRSA from animals to animal handlers. Thus, the prevalence of AMR in S. aureus from animal sources in Malaysia should 
be monitored closely. Nonetheless, most of the $S$. aureus samples were generally susceptible to the tested antibiotics and lacked virulence factors, suggesting the isolates were of less pathogenic significance to humans [40].

Molecular typing of the $S$. aureus is important to understand the dissemination and epidemiology of bacteria. In the present study, spa typing was used to identify the genotypes and determine the relatedness of the isolated MDRSA. According to a study in 2018, the most prominent spa types among clinical S. aureus isolates in the Asia region were $\mathrm{t} 307$ and t002 [41]. Meanwhile, the most prominent spa type in clinical isolates in Malaysia was t307 [41]. The previous findings were different to this study, which demonstrated that the most prominent spa types identified were t189 $(16.6 \% ; 5 / 31)$ and $4171(16.6 \% ; 5 / 31)$. The presence of MRSA and MSSA t189 was previously reported among S. aureus isolated from hospital patients, university students and poultry farm workers in Malaysia, suggesting the widespread of this genotype among S. aureus in local settings [27,42]. Moreover, S. aureus t189 was also reported as the prominent genotype in clinical isolates from the Netherlands, Italy, Korea, China and Taiwan [41]. In addition, the present study is the first to report the presence of MRSA t14171 among Malaysian animal handlers. In the past, spa type t4171 was only reported in clinical MSSA isolates and MSSA/MRSA isolates from swine in Malaysia [17,42]. The finding of both MRSA t4171 and MSSA t4171 in animal handlers suggests that these genotypes may be unique and common in various local settings. Other spa types, such as $\mathrm{t} 548, \mathrm{t} 050, \mathrm{t} 3239, \mathrm{t} 084, \mathrm{t} 095, \mathrm{t} 3080, \mathrm{t} 9531, \mathrm{t} 605, \mathrm{t} 550$, and $\mathrm{t} 714$, detected in this study were reported for the first time in Malaysia. Even though some of the isolates shared the similar spa types, their antimicrobial resistance and virulence gene profiles are different, showing that the MDR trait may not be specific to certain strains or locations. Thus, continuous surveillance of $S$. aureus in various communities and environments should be carried out in order to have a more holistic insight on the distribution and emergence of AMR strains. Future genotyping study of local MDRSA strains such as MRSA t4171 using multilocus sequence typing (MLST) and whole genome sequencing (WGS) techniques should be carried out to provide data for better understanding and comparison with international MSSA/MRSA strains. Furthermore, policies and programs that promote the responsible usage of antimicrobials as well as good bacterial infection prevention and control measures among animal handlers in Peninsular Malaysia should be strengthened to prevent the emergence of AMR in local animals.

\section{Materials and Methods}

\subsection{Swab Sample Collection, Isolation and Genotypic Identification of Bacteria}

The sample size of animal handlers was determined using GraphPad StatMate@ software (5\% absolute precision and $95 \%$ level of confidence) for cross-sectional and random sampling. The expected S. aureus carriage rate of $30 \%$ was used to determine the maximum sample size. Informed consent was obtained from all recruited volunteers included in the study. In the present study, 846 swab samples (423 nasal and 423 oral swabs) were collected from 423 animal handlers in various states of Malaysia (Terengganu, Kelantan, Pahang, Johor, Selangor, Perak, Penang, Kedah, Negeri Sembilan, Perlis, Malacca and Kuala Lumpur) from the period of September 2019 to December 2019. In the present study, an animal handler was defined as an individual with frequent exposure to domestic livestock and companion animals, such as animal farmers $(n=343)$, pet owners $(n=70)$ and veterinarians $(n=10)$. Nasal swab samples were collected by inserting the swab (approximately $2 \mathrm{~cm}$ ) into the nostril. The swab was rotated several times against the nasal wall and the procedure was repeated in the other nostril using the same swab. Meanwhile, oral swabs were taken by swabbing the back of the throat, roof of the mouth and cheek for several seconds. Swab samples were carefully placed into the falcon tubes containing transport medium and kept in a cooler box at around $4{ }^{\circ} \mathrm{C}$ and sent to the Universiti Sultan Zainal Abidin (UniSZA) Microbiology laboratory for further analysis. The swab samples were then streaked onto mannitol salt agar (Thermo Fisher Scientific, Waltham, MA, USA) and incubated at $37^{\circ} \mathrm{C}$ for up to $48 \mathrm{~h}$. Yellow colonies with yellow zones growing on 
mannitol salt agar were considered to be putative $S$. aureus colonies. The putative $S$. aureus colonies were then sub-cultured on nutrient agar (Thermo Fisher Scientific, Waltham, MA, USA) supplemented with $6.5 \%$ sodium chloride $(\mathrm{NaCl})$ and incubated at $37{ }^{\circ} \mathrm{C}$ for $24 \mathrm{~h}$. Putative $S$. aureus colonies were then subjected to DNA extraction using the heat lysis method, where the bacterial colonies were suspended in $120 \mu \mathrm{L}$ distilled water and boiled for $5 \mathrm{~min}$ at $95^{\circ} \mathrm{C}$ [12]. The extracted DNA was kept at $-20^{\circ} \mathrm{C}$ prior to analysis. The PCR detection method was used to screen for the presence of $S$. aureus and MRSA. The primers used for the detection of $S$. aureus and MRSA were nuc ( $S$. aureus species-specific gene) and methicillin-resistant genes $(m e c A$ and $m e c C)$, respectively, as shown in Table 5 [43,44]. In this study, $3 \mu \mathrm{L}$ of DNA templates of bacterial isolates were added to $7 \mu \mathrm{L}$ PCR mixtures containing primers $(0.1 \mu \mathrm{L}$ forward and 0.1 reverse primer), nuclease-free deionized water $(1.8 \mu \mathrm{L})$ and $5 \mu \mathrm{L}$ of MyTaq HS Red Mix (Bioline, London, UK). The PCR protocol was run using the Applied Biosystems Veriti 96 Well Thermal Cycler (Thermo Fisher Scientific, Waltham, MA, USA). Amplified PCR products along with a 100 bp DNA Ladder (Promega, Madison, MI, USA) were loaded into $2.0 \%(w / v)$ agarose gel stained with GelRed Nucleic Acid Gel Stain (Biotium Inc., Fremont, CA, US) and gel electrophoresis was run in 1X trisborate-EDTA (TBE) running buffer (Bioline, UK) at $80 \mathrm{~V}$ for $2 \mathrm{~h}$. The gels were visualized using Fujifilm LAS-4000 gel documentation system (Fujifilm Life Science, Cambridge, MA, US). Bacteria isolates that showed the presence of DNA bands at $278 \mathrm{bp}$ (nuc gene) were considered to be $S$. aureus. isolates that displayed that the presence of both nuc (278 bp) and mecA (533 bp) were positively confirmed as MRSA. Meanwhile, bacterial isolates that carried both nuc (278 bp) and mecC (138 bp) genes were identified as LA-MRSA. Bacterial isolates with the presence of nuc genes only were referred to as methicillin-susceptible $S$. aureus (MSSA). S. aureus ATCC 700699 was used as the control strain, and were used as the positive control for nuc and mecA genes detection.

Table 5. List of primers used for the detection of AMR and virulence genes of S. aureus.

\begin{tabular}{|c|c|c|c|c|c|}
\hline No. & Primer & Primer Sequence $\left(5^{\prime}-3^{\prime}\right)$ & Product Size (bp) & $\begin{array}{c}\text { Annealing } \\
\text { Temperature }\left({ }^{\circ} \mathrm{C}\right)\end{array}$ & References \\
\hline 1. & nuc & $\begin{array}{c}\text { F-GCGATTGATGGTGATACGGTT } \\
\text { R-AGCCAAGCCTTGACGAACTAAAGC }\end{array}$ & 278 & 55 & [43] \\
\hline 2. & $\operatorname{mec} A$ & $\begin{array}{l}\text { F-AAAATCGATGGTAAAGGTTGGC } \\
\text { R-AGTTCTGCAGTACCGGATTTGC }\end{array}$ & 533 & 55 & [43] \\
\hline 3. & mecC & $\begin{array}{l}\text { F-GAAAAAAAGGCTTAGAACGCCTC } \\
\text { R-GAAGATCTTTTCCGTTTTCAGC }\end{array}$ & 138 & 59 & [44] \\
\hline 4. & tetK & $\begin{array}{l}\text { F-TCGATAGGAACAGCAGTA } \\
\text { R-CAGCAGATCCTACTCCTT }\end{array}$ & 169 & 55 & [45] \\
\hline 5. & tet $O$ & $\begin{array}{l}\text { F-AACTTAGGCATTCTGGCTCAC } \\
\text { R-TCCCACTGTTCCATATCGTCA }\end{array}$ & 515 & 55 & [45] \\
\hline 6. & tet $M$ & $\begin{array}{l}\text { F-GTGGACAAAGGTACAACGAG } \\
\text { R-CGGTAAAGTTCGTCACACAC }\end{array}$ & 406 & 55 & [45] \\
\hline 7. & tet $L$ & $\begin{array}{l}\text { F-TCGTTAGCGTGCTGTCATTC } \\
\text { R-GTATCCCACCAATGTAGCCG }\end{array}$ & 267 & 55 & [45] \\
\hline 8. & $m s r A$ & $\begin{array}{c}\text { F-GGCACAATAAGAGTGTTTAAAGG } \\
\text { R-AAGTTATATCATGAATAGATTGTCCTGTT }\end{array}$ & 940 & 50 & [46] \\
\hline 9. & ermA & $\begin{array}{l}\text { F-GTTCAAGAACAATCAATACAGAG } \\
\text { R-GGATCAGGAAAAGGACATTTTAC }\end{array}$ & 421 & 52 & [46] \\
\hline 10. & ermB & $\begin{array}{c}\text { F-CCGTTTACGAAATTGGAACAGGTAAAGGGC } \\
\text { R-GAATCGAGACTTGAGTGTGC }\end{array}$ & 359 & 55 & [46] \\
\hline 11. & ermC & $\begin{array}{l}\text { F-GCTAATATTGTTTAAATCGTCAATTCC } \\
\text { R-GGATCAGGAAAAGGACATTTTAC }\end{array}$ & 572 & 52 & [46] \\
\hline 12. & $\operatorname{van} A$ & $\begin{array}{l}\text { F-ATGAATAGAATAAAAGTTGC } \\
\text { R-TCACCCCTTTAACGCTAATA }\end{array}$ & 1032 & 62 & [46] \\
\hline 13. & scn & $\begin{array}{l}\text { F-AGCACAAGCTTGCCAACATCG } \\
\text { R-TTAATATTTACTTTTTAGTGC }\end{array}$ & 258 & 50 & [20] \\
\hline
\end{tabular}


Table 5. Cont.

\begin{tabular}{|c|c|c|c|c|c|}
\hline No. & Primer & Primer Sequence $\left(5^{\prime}-3^{\prime}\right)$ & Product Size (bp) & $\begin{array}{c}\text { Annealing } \\
\text { Temperature }\left({ }^{\circ} \mathrm{C}\right)\end{array}$ & References \\
\hline \multirow[t]{2}{*}{14.} & sak & F-AAGGCGATGACGCGAGTTAT & 223 & 50 & [20] \\
\hline & & R-GCGCTTGGATCTAATTCAAC & & & \\
\hline \multirow[t]{2}{*}{15.} & sea & F-AGATCATTCGTGGTATAACG & 408 & 50 & [20] \\
\hline & & R-TTAACCGAAGGTTCTGTAGA & & & \\
\hline 16. & sep & F-AATCATAACCAACCGAATCA & 500 & 50 & [20] \\
\hline \multirow[t]{2}{*}{17.} & $\operatorname{chp}$ & F-GAAAAAGAAATTAGCAACAACAG & 410 & 50 & \\
\hline & & R-CATAAGATGATTTAGACTCTCC & & & [47] \\
\hline \multirow[t]{2}{*}{18.} & luk-PV & F-ATCATTAGGTAAAATGTCTGGACATGATCCA & 433 & 55 & [48] \\
\hline & & R-GCATCAAGTGTATTGGATAGCAAAAGC & & & \\
\hline \multirow[t]{2}{*}{19.} & tst & F-TTATCGTAAGCCCTTTGTTG & 398 & 60 & [49] \\
\hline & & R-TAAAGGTAGTTCTATTGGAGTAGG & & & \\
\hline \multirow[t]{2}{*}{20.} & eta & F-CTAGTGCATTTGTTATTCAA & 119 & 55 & [50] \\
\hline & & R-TGCATTGACACCATAGTACT & & & \\
\hline \multirow[t]{2}{*}{21.} & $e t b$ & F-ACGGCTATATACATTCAATT & 200 & 55 & {$[50]$} \\
\hline & & R-TCCATCGATAATATACCTAA & & & \\
\hline
\end{tabular}

\subsection{Antibiotic Susceptibility Test (AST) of S. aureus}

The antibiotic susceptibility of $S$. aureus isolates was determined using the Kirby-Bauer test on Mueller-Hinton agar (Oxoid, UK), according to the recommendations given by the Clinical and Laboratory Standards Institute (CLSI). The AST was performed using 18 antibiotics as listed in Table 1 . The diameter of the inhibition zones for each isolate was measured and compared to antimicrobial susceptibility breakpoints listed in CLSI guidelines [51]. S. aureus ATCC 700699 was used as the control strain. S. aureus isolates that showed resistance against three or more categories of antibiotics were classified as multidrug-resistant $S$. aureus (MDRSA) [6].

\subsection{Genotypic Characterization of S. aureus}

All MRSA and MDRSA were further screened using PCR to detect the presence of different antimicrobial resistance genes, including tetracycline-resistant (tet $\mathrm{K}$, tet $\mathrm{L}$, tet $\mathrm{M}$ and tet $\mathrm{O}$ ), erythromycin-resistant (erm $A, \operatorname{erm} B, \operatorname{erm} C$ and $m s r A)$, and vancomycin-resistant genes $(\mathrm{van} A)$ as mentioned in Table $4[45,46]$. The prevalence of nine different virulence genes (Table 4), including the immune evasion cluster (scn, chp, sak, sea and sep), exfoliative toxins $(e t a, e t b)$, PVL toxin $(p v l)$ and TSST-1 (tst) were also investigated [20,48-50]. In regard to IEC genes, $S$. aureus isolates were later classified into eight different IEC types according to the combination of genes detected. The presence of the scn gene was mandatory for the consideration of the IEC types [20].

\subsection{Spa Typing of MDRSA}

Thirty isolates of non-repetitive MDRSA (both MRSA and MDR-MSSA) were further investigated using spa typing. The $\mathrm{X}$ region of the spa gene of MDRSA isolate was amplified using PCR with the primers spa-1095F (5'-AGACGATCCTTCGGTGAGC-3') and spa1517R (5'-GCTTTTGCAATGTCATTTACTG-3') [52]. The PCR amplification started at initial denaturation at $94{ }^{\circ} \mathrm{C}$ for $3 \mathrm{~min}$ followed by 35 cycles of $94{ }^{\circ} \mathrm{C}$ for $30 \mathrm{~s}, 54{ }^{\circ} \mathrm{C}$ for $1 \mathrm{~min}$ and $72{ }^{\circ} \mathrm{C}$ for $30 \mathrm{~s}$, with the final extension at $72{ }^{\circ} \mathrm{C}$ for $7 \mathrm{~min}$. The amplified PCR products were purified and sent to Bio Basic research laboratory (Singapore) for DNA sequencing. The sequences were analysed using BioNumerics 8.0 (Applied Maths, Austin, TX, US) to assign the spa type of $S$. aureus isolates. The DNA sequence data of $S$. aureus isolate with unknown spa repeat and type were uploaded to Ridom Spa Server website (http: / / spaserver.ridom.de, last accessed at 6 November 2020) for the assignment of new spa type. 


\subsection{Statistical Analysis}

The occurrence rate of the S. aureus and MRSA as well as different antimicrobial and virulence genes was counted and presented in percentages (\%). The $95 \%$ confidence interval (CI) of the occurrence rates of S. aureus, MRSA and MDRSA among the animal handlers was calculated. Categorical data were analysed using Chi-square or Fisher's exact test (Minitab 19, 2019), with the 95\% confidence interval $(p<0.05)$ being set to indicate the significant difference. The antibiotic resistance percentage was calculated as the proportion of isolates tested that had an inhibition zone below the respective antibiotic breakpoint. The relationships between the antibiotic exposure and overall antibiotic resistance of the isolated S. aureus were assessed via the multiple antimicrobial resistance index (MARI). The MARI was calculated as the proportion of antibiotics to which S. aureus isolate was phenotypically resistant.

\section{Conclusions}

The present study revealed the carriage rate of S. aureus (30.5\%) and MRSA (1.2\%) of animal handlers from Peninsular Malaysia. The findings also showed that $S$. aureus isolates were highly resistant against penicillin and amoxicillin while showing full susceptibility against gentamicin and linezolid. Subsequently, $19.4 \%$ of S. aureus isolates were categorized as MDRSA, demonstrating the low prevalence of $S$. aureus with multiple drug-resistant traits among Malaysian animal handlers. Nonetheless, different numbers of antimicrobial resistance (mecA, tet $K$, tet $M$, tet $L, \operatorname{erm} A, \operatorname{erm} B, \operatorname{erm} C$ and $m s r A)$ and IEC (scn, sak, chp, sea and sep) genes were detected among the $S$. aureus isolates, raising concern regarding the further emergence of AMR bacteria among animal handlers through the dissemination of antibiotic-resistant genes. Furthermore, molecular typing showed the presence of seventeen different spa genotypes were detected among the MDRSA, with t189 $(16.7 \%)$ and $\mathrm{t} 2174$ $(16.7 \%)$ been the prominent genotypes. The findings from this study suggest the emergence of MDRSA with great genetic diversity and antimicrobial resistance profiles among animal handlers from different locations of Peninsular Malaysia.

Supplementary Materials: The following supporting information can be downloaded at: https:/ / www.mdpi.com/article/10.3390/antibiotics11010103/s1, Table S1: Demographic data and molecular profile of MDRSA isolates $(n=30)$.

Author Contributions: Conceptualization, M.C. and M.F.G.; Funding acquisition, M.F.G.; Investigation, M.C., M.Z.S., A.H.K.B., I.R., L.Z.L., Y.L. and P.M.; Methodology, M.C., M.Z.S., N.M.M. and M.F.G.; Project administration, M.F.G.; Resources, N.M.M., S.C., S.M.Z.A. and M.F.G.; Supervision, M.F.G.; Writing—original draft, M.C.; Writing—review and editing, M.C., S.C., S.M.Z.A. and M.F.G. All authors have read and agreed to the published version of the manuscript.

Funding: This research was funded by Research Acculturation Grant Scheme (RAGS), Grant number RAGS/1/2015/SG0/UNISZA/02/1.

Institutional Review Board Statement: The study was conducted according to the guidelines of the Declaration of Helsinki, and approved by the Universiti Sultan Zainal Abidin Human Research Ethnic Committee (UHREC) under the protocol code: UniSZA/UHREC/2019/85.

Informed Consent Statement: Informed consent was obtained from all subjects involved in the study.

Data Availability Statement: The data presented in this study are available in the article and Supplementary Materials.

Conflicts of Interest: The authors declare no conflict of interest.

\section{References}

1. Chai, M.H.; Sukiman, M.Z.; Najib, N.M.; Mohabbar, N.A.; Azizan, N.A.N.M.; Mohamad, N.M.; Ariffin, S.M.Z.; Ghazali, M.F. Molecular detection and antibiogram of Staphylococcus aureus in rabbits, rabbit handlers, and rabbitry in Terengganu, Malaysia. J. Adv. Vet. Anim. Res. 2021, 8, 388-395. [CrossRef] [PubMed]

2. Chai, M.H.; Faiq, T.A.M.; Ariffin, S.M.Z.; Suhaili, Z.; Sukiman, M.Z.; Ghazali, M.F. Prevalence of methicillin resistant Staphylococcus aureus in raw goat milks from selected farms in Terengganu, Malaysia. Trop. Anim. Sci. J. 2020, 43, 64-69. [CrossRef] 
3. Prestinaci, F.; Pezzotti, P.; Pantosti, A. Antimicrobial resistance: A global multifaceted phenomenon. Pathog. Glob. Health 2015, 109, 309-318. [CrossRef] [PubMed]

4. Lakhundi, S.; Zhang, K. Methicillin-resistant Staphylococcus aureus: Molecular characterization, evolution, and epidemiology. Clin. Microbiol. Infect. 2018, 31, 1-103. [CrossRef]

5. Moreno-Grúa, E.; Pérez-Fuentes, S.; Muñoz-Silvestre, A.; Viana, D.; Fernández-Ros, A.B.; Sanz-Tejero, C.; Corpa, J.M.; Selva, L. Characterization of livestock-associated methicillin-resistant Staphylococcus aureus isolates obtained from commercial rabbitries located in the Iberian Peninsula. Front. Microbiol. 2018, 9, 1812. [CrossRef] [PubMed]

6. Chai, M.H.; Majib, M.E.A.; Sukiman, M.Z.; Najib, N.M.; Mohabbar, N.A.; Azizan, N.A.N.M.; Mohamad, N.M.; Ariffin, S.M.Z.; Ghazali, M.F. Molecular identification of multidrug-resistant Staphylococcus aureus (MDRSA) carriage and pattern of antibiotic resistance from rabbit, rabbit handler and rabbitry in the east coast region of Malaysia. Biosci. Res. 2021, 18, 380-387.

7. Zomer, T.P.; Wielders, C.C.H.; Veenman, C.; Hengeveld, P.; Van der Hoek, W.; de Greeff, S.C.; Smit, L.A.M.; Heederik, D.J.; Yzermans, C.J.; Bosch, T.; et al. MRSA in persons not living or working on a farm in a livestock-dense area: Prevalence and risk factors. J. Antimicrob. Chemother. 2017, 72, 893-899. [CrossRef] [PubMed]

8. Oppliger, A.; Moreillon, P.; Charrière, N.; Giddey, M.; Morisset, D.; Sakwinska, O. Antimicrobial resistance of Staphylococcus aureus strains acquired by pig farmers from pigs. Appl. Environ. Microbiol. 2012, 78, 8010-8014. [CrossRef]

9. Wardyn, S.E.; Forshey, B.M.; Farina, S.A.; Kates, A.E.; Nair, R.; Quick, M.K.; Wu, J.Y.; Hanson, B.M.; O’Malley, S.M.; Shows, H.W.; et al. Swine farming is a risk factor for infection with and high prevalence of carriage of multidrug-resistant Staphylococcus aureus. Clin. Infect. Dis. 2015, 61, 59-66. [CrossRef]

10. Haran, K.P.; Godden, S.M.; Boxrud, D.; Jawahir, S.; Bender, J.B.; Sreevatsan, S. Prevalence and characterization of Staphylococcus aureus, including methicillin-resistant Staphylococcus aureus, isolated from bulk tank milk from Minnesota dairy farms. J. Clin. Microbiol. 2012, 50, 688-695. [CrossRef]

11. Fluit, A.C. Livestock-associated Staphylococcus aureus. Clin. Microbiol. Infect. 2012, 18, 735-744. [CrossRef]

12. Suhaili, Z.; Rafee, P.A.; Mat Azis, N.; Yeo, C.C.; Nordin, S.A.; Abdul Rahim, A.R.; Al-Obaidi, M.M.J.; Mohd Desa, M.N. Characterization of resistance to selected antibiotics and Panton-Valentine leukocidin-positive Staphylococcus aureus in a healthy student population at a Malaysian University. Germs 2018, 8, 21-30. [CrossRef]

13. Cuny, C.; Wieler, L.H.; Witte, W. Livestock-Associated MRSA: The impact on humans. Antibiotics 2015, 4, 521-543. [CrossRef]

14. Foster, T.J. Antibiotic resistance in Staphylococcus aureus. Current status and future prospects. FEMS Microbiol. Rev. 2017, 41, 430-449. [CrossRef]

15. Kozajda, A.; Jeżak, K.; Kapsa, A. Airborne Staphylococcus aureus in different environments-A review. Environ. Sci. Pollut. Res. 2019, 26, 34741-34753. [CrossRef]

16. Peacock, S.J.; Paterson, G.K. Mechanisms of methicillin resistance in Staphylococcus aureus. Annu. Rev. Biochem. 2015, 84, 577-601. [CrossRef]

17. Chai, M.H.; Sukiman, M.Z.; Chan, Y.F.; Liew, Y.W.; Lai, L.Z.H.; Mohamad, N.M.; Ariffin, S.M.Z.; Ghazali, M.F. Detection, antibiogram and molecular characterization of MRSA and MSSA isolated from swine. IOP Conf. Ser. Earth Environ. Sci. 2021, 888, 012064. [CrossRef]

18. Suhaili, Z.; Yeo, C.C.; Ghazali, M.F.; Chew, C.H.; Zainul, A.Z.; Mazen, M.J.A.-O.; Nordin, S.A.; Mohd Desa, M.N. Nasal colonisation, antimicrobial susceptibility and genotypic pattern of Staphylococcus aureus among agricultural biotechnology students in Besut, Terengganu, east coast of Malaysia. Trop. Med. Int. Health 2018, 23, 905-913. [CrossRef]

19. Cuny, C.; Abdelbary, M.; Layer, F.; Werner, F.; Witte, W. Prevalence of the immune evasion gene cluster in Staphylococcus aureus CC398. Vet. Microbiol. 2015, 177, 219-223. [CrossRef]

20. Van Wamel, W.J.B.; Rooijakkers, S.H.M.; Ruyken, M.; Van Kessel, K.P.M.; Van Strijp, J.A.G. The innate immune modulators Staphylococcal complement inhibitor and chemotaxis inhibitory protein of Staphylococcus aureus are located on $\beta$-hemolysinconverting bacteriophages. J. Bacteriol. 2006, 188, 1310-1315. [CrossRef]

21. Hau, S.J.; Sun, J.; Davies, P.R.; Frana, T.S.; Nicholson, T.L. Comparative prevalence of immune evasion complex genes associated with $\beta$-hemolysin converting bacteriophages in MRSA ST5 isolates from swine, swine facilities, humans with swine contact, and humans with no swine contact. PLoS ONE 2015, 10,1-13. [CrossRef]

22. Bien, J.; Sokolova, O.; Bozko, P. Characterization of virulence factors of Staphylococcus aureus: Novel function of known virulence factors that are implicated in activation of airway epithelial proinflammatory response. J. Pathog. 2011, 2011, 1-13. [CrossRef] [PubMed]

23. Mohseni, M.; Rafiei, F.; Ghaemi, E.A. High frequency of exfoliative toxin genes among Staphylococcus aureus isolated from clinical specimens in the north of Iran: Alarm for the health of individuals under risk. Iran. J. Microbiol. 2018, 10, 158-165. [PubMed]

24. Che Hamzah, A.M.; Yeo, C.C.; Puah, S.M.; Chua, K.H.; Chew, C.H. Staphylococcus aureus infections in Malaysia: A review of antimicrobial resistance and characteristics of the clinical isolates, 1990-2017. Antibiotics 2019, 8, 128. [CrossRef] [PubMed]

25. Jayaweera, J.A.A.S.; Kumbukgolla, W.W. Antibiotic resistance patterns of methicillin-resistant Staphylococcus aureus (MRSA) isolated from livestock and associated farmers in Anuradhapura, Sri Lanka. Germs 2017, 7, 132-139. [CrossRef]

26. Ye, X.; Fan, Y.; Wang, X.; Liu, W.; Yu, H.; Zhou, J.; Chen, S.; Yao, Z. Livestock-associated methicillin and multidrug resistant $S$. aureus in humans is associated with occupational pig contact, not pet contact. Sci. Rep. 2016, 6, 1-9. [CrossRef] 
27. Neela, V.; Ghaznavi-Rad, E.; Ghasemzadeh-Moghaddam, H.; Nor Shamsudin, M.; van Belkum, A.; Karunanidhi, A. Frequency of methicillin resistant Staphylococcus aureus in the noses of Malaysian chicken farmers and their chicken. Iran. J. Vet. Res. 2013, 14, 226-231.

28. Aklilu, E.; Zakaria, Z.; Hassan, L.; Chen, H.C. Molecular relatedness of methicillin-resistant S. aureus isolates from staff, environment and pets at university veterinary hospital in Malaysia. PLoS ONE 2012, 7, e43329. [CrossRef]

29. Che Hamzah, A.M.; Yeo, C.C.; Puah, S.M.; Chua, K.H.; Rahman, N.I.A.; Abdullah, F.H.; Othman, N.; Chew, C.H. Tigecycline and inducible clindamycin resistance in clinical isolates of methicillin-resistant Staphylococcus aureus from Terengganu, Malaysia. J. Med. Microbiol. 2019, 68, 1299-1305. [CrossRef]

30. Jaja, I.F.; Jaja, C.I.; Chigor, N.V.; Anyanwu, M.U.; Maduabuchi, E.K.; Oguttu, J.W.; Green, E. Antimicrobial resistance phenotype of Staphylococcus aureus and Escherichia coli isolates obtained from meat in the formal and informal sectors in South Africa. Biomed. Res. Int. 2020, 2020, 3979482. [CrossRef]

31. Ariffin, S.M.Z.; Hasmadi, N.; Syawari, N.M.; Sukiman, M.Z.; Ariffin, M.F.T.; Chai, M.H.; Ghazali, M.F. Prevalence and antibiotic susceptibility pattern of Staphylococcus aureus, Streptococcus agalactiae and Escherichia coli in dairy goats with clinical and subclinical mastitis. J. Anim. Health Prod. 2019, 7, 32-37. [CrossRef]

32. Friese, A.; Schulz, J.; Zimmermann, K.; Tenhagen, B.A.; Fetsch, A.; Hartung, J.; Rösler, U. Occurrence of livestock-associated methicillin-resistant Staphylococcus aureus in turkey and broiler barns and contamination of air and soil surfaces in their vicinity. Appl. Environ. Microbiol. 2013, 79, 2759-2766. [CrossRef]

33. Hetem, D.J.; Westh, H.; Boye, K.; Jarløv, J.O.; Bonten, M.J.M.; Bootsma, M.C.J. Nosocomial transmission of community-associated methicillin-resistant Staphylococcus aureus in Danish hospitals. J. Antimicrob. Chemother. 2012, 67, 1775-1780. [CrossRef]

34. Silva, V.; Ferreira, E.; Manageiro, V.; Reis, L.; Tejedor-Junco, M.T.; Sampaio, A.; Capelo, J.L.; Caniça, M.; Igrejas, G.; Poeta, P. Distribution and clonal diversity of Staphylococcus aureus and other staphylococci in surface waters: Detection of ST425-t742 and ST130-t843 mecC-positive MRSA strains. Antibiotics 2021, 10, 1416. [CrossRef]

35. Mulders, M.N.; Haenen, A.P.J.; Geenen, P.L.; Vesseur, P.C.; Poldervaart, E.S.; Bosch, T.; Huijsdens, X.W.; Hengeveld, P.D.; DamDeisz, W.D.C.; Graat, E.A.M.; et al. Prevalence of livestock-associated MRSA in broiler flocks and risk factors for slaughterhouse personnel in The Netherlands. Epidemiol. Infect. 2010, 138, 743. [CrossRef]

36. Sineke, N.; Asante, J.; Amoako, D.G.; Luther, A.; Abia, K.; Perrett, K.; Bester, L.A.; Essack, S.Y. Staphylococcus aureus in intensive pig production in South Africa: Antibiotic resistance, virulence determinants, and clonality. Pathogens 2021, 10, 317. [CrossRef]

37. Ariffin, M.F.; Hasmadi, N.; Chai, M.H.; Ghazali, M.F.; Ariffin, S.M.Z. Prevalence and antimicrobial sensitivity pattern of Staphylococcus aureus isolated from clinical and subclinical mastitis in small ruminant in Besut and Setiu, Terengganu, Malaysia. Malays. J. Microbiol. 2020, 16, 104-110. [CrossRef]

38. Corona, F.; Martinez, J.L. Phenotypic resistance to antibiotics. Antibiotics 2013, 2, 237-255. [CrossRef]

39. Verkaik, N.J.; Benard, M.; Boelens, H.A.; De Vogel, C.P.; Nouwen, J.L.; Verbrugh, H.A.; Melles, D.C.; Van Belkum, A.; Van Wamel, W.J.B. Immune evasion cluster-positive bacteriophages are highly prevalent among human Staphylococcus aureus strains, but they are not essential in the first stages of nasal colonization. Clin. Microbiol. Infect. 2011, 17, 343-348. [CrossRef]

40. Hirose, M.; Aung, M.S.; Fukuda, A.; Yahata, S.; Fujita, Y.; Saitoh, M. Antimicrobial resistance and molecular epidemiological characteristics of methicillin-resistant and susceptible Staphylococcal isolates from oral cavity of dental patients and staff in Northern Japan. Antibiotics 2021, 10, 1316. [CrossRef]

41. Asadollahi, P.; Farahani, N.N.; Mirzaii, M.; Khoramrooz, S.S.; van Belkum, A.; Asadollahi, K.; Dadashi, M.; Darban-Sarokhalil, D. Distribution of the most prevalent spa types among clinical isolates of methicillin-resistant and -susceptible Staphylococcus aureus around the world: A review. Front. Microbiol. 2018, 9, 1-16. [CrossRef]

42. Jones, S.U.; Chua, K.H.; Chew, C.H.; Yeo, C.C.; Abdullah, F.H.; Othman, N.; Kee, B.P.; Puah, S.M. Spa diversity of methicillinresistant and -susceptible Staphylococcus aureus in clinical strains from Malaysia: A high prevalence of invasive European spa-type. PeerJ 2021, 9, e11195. [CrossRef]

43. Saiful, A.J.; Mastura, M.; Suhaili, Z.; Mazurah, M.I.; Shuhaimi, M.; Ali, A.M. Detection of methicillin-resistant Staphylococcus aureus using mecA/nuc genes and antibiotic susceptibility profile of Malaysian clinical isolates. World J. Microbiol. Biotechnol. 2006 22, 1289-1294. [CrossRef]

44. Stegger, M.; Liu, C.M.; Larsen, J.; Soldanova, K.; Aziz, M.; Contente-Cuomo, T.; Mammina, C.; van Belkum, A.; Salmenlinna, S.; Laurent, F.; et al. Rapid differentiation between livestock-associated and livestock-independent Staphylococcus aureus CC398 clades. PLOS ONE 2013, 8, e79645. [CrossRef]

45. Ng, L.; Martin, I.; Alfa, M.; Mulvey, M. Multiplex PCR for the detection of tetracycline resistant genes. Mol. Cell. Probes. 2001, 15, 209-215. [CrossRef]

46. Ma, Y.; Zhao, Y.; Tang, J.; Tang, C.; Chen, J.; Liu, J. Antimicrobial susceptibility and presence of resistance \& enterotoxins/enterotoxinlikes genes in Staphylococcus aureus from food. CYTA J. Food 2018, 16, 76-84. [CrossRef]

47. De Haas, C.J.C.; Veldkamp, K.E.; Peschel, A.; Weerkamp, F.; van Wamel, W.J.B.; Heezius, E.C.J.M.; Poppelier, M.J.J.G.; van Kessel, K.P.M.; van Strijp, J.A.G. Chemotaxis inhibitory protein of Staphylococcus aureus, a bacterial antiinflammatory agent. J. Exp. Med. 2004, 199, 687-695. [CrossRef]

48. Lina, G.; Quaglia, A.; Reverdy, M.E.; Leclercq, R.; Vandenesch, F.; Etienne, J. Distribution of genes encoding resistance to macrolides, lincosamides, and streptogramins among Staphylococci. Antimicrob. Agents Chemother. 1999, 43, 1062-1066. [CrossRef] [PubMed] 
49. Peacock, S.J.; Moore, C.E.; Justice, A.; Kantzanou, M.; Story, L.; Mackie, K.; O’Neill, G.; Day, N.P.J. Virulent combinations of adhesin and toxin genes in natural populations of Staphylococcus aureus. Infect. Immun. 2002, 70, 4987-4996. [CrossRef] [PubMed]

50. Tokajian, S.; Haddad, D.; Andraos, R.; Hashwa, F.; Araj, G. Toxins and antibiotic resistance in Staphylococcus aureus isolated from a major hospital in Lebanon. ISRN Microbiol. 2011, 2011, 1-9. [CrossRef] [PubMed]

51. Clinical and Laboratory Standards Institute (CLSI). Performance Standards for Antimicrobial Susceptibility Testing, 28th ed.; CLSI supplement M100; Clinical and Laboratory Standards Institute: Wayne, PA, USA, 2018; pp. 54-62.

52. Harmsen, D.; Claus, H.; Witte, W.; Claus, H.; Turnwald, D.; Vogel, U. Typing of methicillin-resistant Staphyloccocus aureus in a university hospital setting by using novel software for spa repeat determination and database management. J. Clin. Microbiol. 2003, 41, 5442-5448. [CrossRef] 